\title{
Familial Aggregation in Patients with Non-Alcoholic Steatohepatitis
}

\author{
Katsutoshi Tokushige, Satoru Yatsuji, Etsuko Hashimoto, Ayae Kabutake, Maki Tobari, \\ Makiko Taniai and Keiko Shiratori
}

\begin{abstract}
We encountered three families that showed NASH accumulation. In family \#1, a 21-year-old son and 10year-old daughter were diagnosed with nonalcoholic steatohepatitis (NASH). They shared two adiponectingene single nucleotide polymorphisms (SNP). In family \#2, a 51-year-old mother and 27-year-old son were diagnosed with NASH and shared the SNPs of other genes. In family \#3, a 66-year-old mother and 34-yearold son were diagnosed with NASH and shared the SNPs of other genes. SNP sites differed among the three families, suggesting that the genes associated with the occurrence of NASH might be different in each patient.
\end{abstract}

Key words: NASH, SNP, familial aggregation

(Inter Med 47: 405-410, 2008)

(DOI: 10.2169/internalmedicine.47.0476)

\section{Introduction}

In lifestyle-related diseases such as type 2 diabetes mellitus (DM/) hypertension, accumulation in a family is often observed $(1,2)$. Hara et al reported that two single nucleotide polymorphism (SNP) sites, Intron 2 and Exon 2 of the adiponectin gene, are associated with DM onset and insulin resistance (3). In addition, SNPs of the PPAR $\gamma 2$ gene, calpains 10 (intron polymorphism) gene and adrenergic receptor (Trp64Ayg polymorphism) gene have been reported to be associated with the onset of DM, suggesting that genetic background might be associated with DM (4-6). In hypertension, a polymorphism of the angiotensinogen gene (M235 T) is reported to be correlated with serum renin levels and to related to hypertension (7). It is reported that insertion/deficiency (I/D) polymorphisms of the angiotensin-converting enzyme (ACE) gene are correlated with the serum ACE level, which is related to cardiovascular disease and essential hypertension (8). These results suggested that the occurrence and progression of lifestyle-related diseases are associated with genetic background as well.

Non-alcoholic fatty liver disease (NAFLD) has recently been recognized as a leading cause of abnormal liver func- tion tests. Its spectrum ranges from simple fatty liver, which is usually a benign and non-progressive condition, to nonalcoholic steatohepatitis (NASH), which may progress to cirrhosis $(9,10)$. Patients with NASH usually have insulin resistance syndrome as well. In addition, NASH is increasingly being recognized as a major cause of cryptogenic cirrhosis and as an indication for liver transplantation. Its etiology remains unclear, but most investigators agree that development of NASH requires underlying steatosis followed by a "second hit" that induces inflammation, fibrosis, or necrosis (10). As NASH is included in metabolic syndrome, familial aggregation is suggested (11-13).

Genetic SNPs of the $\beta 3$ adrenergic receptor gene, microsomal triglyceride transfer protein (MTP) gene, MnSOD gene, and interleukin $1 \beta$ gene are reported to be associated with NASH $(14,15)$. We also demonstrated that SNPs of the TNF promoter region might be associated with the "second hit" of NASH (16). Here, we report three families in which NASH accumulation was observed, and analyze the disease course and gene polymorphisms of these patients.

\section{Case Report}

Between January 1991 and December 2005, 249 patients 
Table 1. Laboratory Data

\begin{tabular}{|c|c|c|c|c|c|c|c|}
\hline & Case1 & Case2 & Case 3 & Case4 & Case 5 & Case 6 & Unit \\
\hline T-bil & 0.7 & 1.5 & 0.3 & 0.8 & 0.6 & 0.8 & $(\mathrm{mg} / \mathrm{dl})$ \\
\hline AST & 280 & 61 & 43 & 134 & 66 & 30 & (IU/l) \\
\hline ALT & 504 & 154 & 98 & 292 & 69 & 65 & (IU/1) \\
\hline$\gamma$-GTP & 54 & 23 & 41 & 184 & 74 & 36 & (IU/l) \\
\hline T-chol & 205 & 139 & 256 & 211 & 249 & 186 & $(\mathrm{mg} / \mathrm{dl})$ \\
\hline TG & 85 & 79 & 83 & 368 & 246 & 224 & $(\mathrm{mg} / \mathrm{dl})$ \\
\hline Plt & 33.7 & 24.5 & 27.2 & 19.4 & 20.3 & 20.9 & $\left(10^{4} / \mathrm{mm}^{3}\right)$ \\
\hline РТ\% & 85.3 & 82.5 & 100 & 89.4 & 93.8 & 100 & $(\%)$ \\
\hline FBS & 99 & 95 & 115 & 91 & 140 & 137 & $(\mathrm{mg} / \mathrm{dl})$ \\
\hline $\mathrm{HbA} 1 \mathrm{c}$ & 4.9 & 4.9 & 6.2 & 5.6 & 8.0 & 7.3 & $(\%)$ \\
\hline IRI & 10.5 & 3.3 & 9.1 & 16.2 & 16.6 & 11.2 & $(\mu \mathrm{U} / \mathrm{ml})$ \\
\hline HOMA-R & 2.57 & 0.77 & 2.58 & 3.64 & 5.74 & 3.79 & \\
\hline HBsAg & $(-)$ & $(-)$ & $(-)$ & $(-)$ & $(-)$ & $(-)$ & \\
\hline $\mathrm{HCV} \mathrm{Ab}$ & $(-)$ & $(-)$ & $(-)$ & $(-)$ & $(-)$ & $(-)$ & \\
\hline $\mathrm{DM}$ & $(-)$ & $(-)$ & $(+)$ & $(-)$ & $(+)$ & $(+)$ & \\
\hline HT & $(-)$ & $(-)$ & $(-)$ & $(-)$ & $(-)$ & $(+)$ & \\
\hline \multicolumn{2}{|c|}{ Hyperlipidemia(-) } & $(-)$ & $(+)$ & $(+)$ & $(-)$ & $(+)$ & \\
\hline
\end{tabular}

were diagnosed as having biopsy-proven NASH at Tokyo Women's Medical University Hospital. Three families were found to have NASH between siblings or between mother and child. The diagnosis of NASH was based on the following criteria: 1) the presence of steatosis (>10\%), lobular inflammation, and ballooning, with or without Mallory bodies and perivenular or pericellular fibrosis; 2) intake of less than $40 \mathrm{~g}$ of ethanol per week, as confirmed by physicians and family members in close contact with the patient; and 3) appropriate exclusion of other liver diseases such as alcoholic liver disease, viral hepatitis, autoimmune hepatitis, druginduced liver disease, primary biliary cirrhosis, primary sclerosing cholangitis, biliary obstruction, and metabolic liver diseases.

Family \#1 (Case 1, 10-year-old girl; Case 2, 21-year-old man)

In the summer of 1999, Case 1, a 10-year-old girl had eaten ice cream every day and had gained $3 \mathrm{~kg}$ of body weight in one month. Because her mother had type 2 DM, a parent-and-child medical examination for DM was performed, revealing hepatic dysfunction. Laboratory and physical data show BMI $21.8 \mathrm{~kg} / \mathrm{m}^{2}$, AST 280, ALT 504 (Table 1). Liver biopsy showed steatohepatitis (Stage 1, Grade 2-3) according to Brunt's NASH classification (17). Thus, she was diagnosed with NASH. Diet and exercise therapy was started, and her serum AST/ALT levels normalized. Her older brother (Case 2) had had mild liver dysfunction since 1999. His body weight had increased by $5 \mathrm{~kg}$ from 2002 to 2003, and his serum AST/ALT levels were markedly increased. Laboratory and physical data showed BMI $23.3 \mathrm{~kg} / \mathrm{m}^{2}$, AST 61, and ALT 154 (Table 1). Liver biopsy showed steatohepatitis (Stage 1, Grade 2), and he was diagnosed with NASH. After diet and exercise therapy, his serum AST/ALT levels improved to the normal range. We investigated the lifestyle and food preference by questionnaires. In cases 1 and 2, both liked to eat snacks and ice cream. Figure 1 shows the family tree of these cases. Their mother had DM. Both her children (cases 1 and 2) were diagnosed with NASH at relatively young ages. In addition, we investigated $10 \mathrm{SNP}$ sites reported to be associated with NASH or DM $(3,14-16)$, and found that both cases shared two adiponectin-gene SNP sites that have been suggested to be related to DM (Table 2).

Family \#2 (Case 3, 51-year-old woman; Case 4, 27-yearold man)

Case 3 had been treated for DM from 1990. Around 2000 , liver dysfunction was discovered, and she was referred to our hospital in 2001. Laboratory and physical data showed BMI $26.4 \mathrm{~kg} / \mathrm{m}^{2}$, AST 43, ALT 98 (Table 1). Liver biopsy showed steatohepatitis (Stage 0-1, Grade 2), and she was diagnosed with NASH. Figure 2 shows her clinical course. We recommended diet and exercise therapy, but her body weight did not decrease. Serum AST/ALT levels increased and decreased in direct proportion to the increase and decrease in her body weight. In 2004, her serum AST/ ALT levels were markedly increased. A second biopsy was performed, showing steatohepatitis (Stage 2, Grade 2-3), and the fibrosis was observed to have progressed during the four years since diagnosis. Her son (Case 4) had had hepatic dysfunction since his late teens. Serum AST/ALT levels, which at one time were normalized, had increased again in 2004, prompting a medical examination at that time. In 2005, his serum AST/ALT levels were increased to $134 / 292$ when his body weight increased from $78 \mathrm{~kg}$ to $82 \mathrm{~kg}$, as shown in Fig. 2. Liver biopsy showed steatohepatitis (Stage 1, Grade 3 ). With his weight loss, liver function improved. In cases 3 


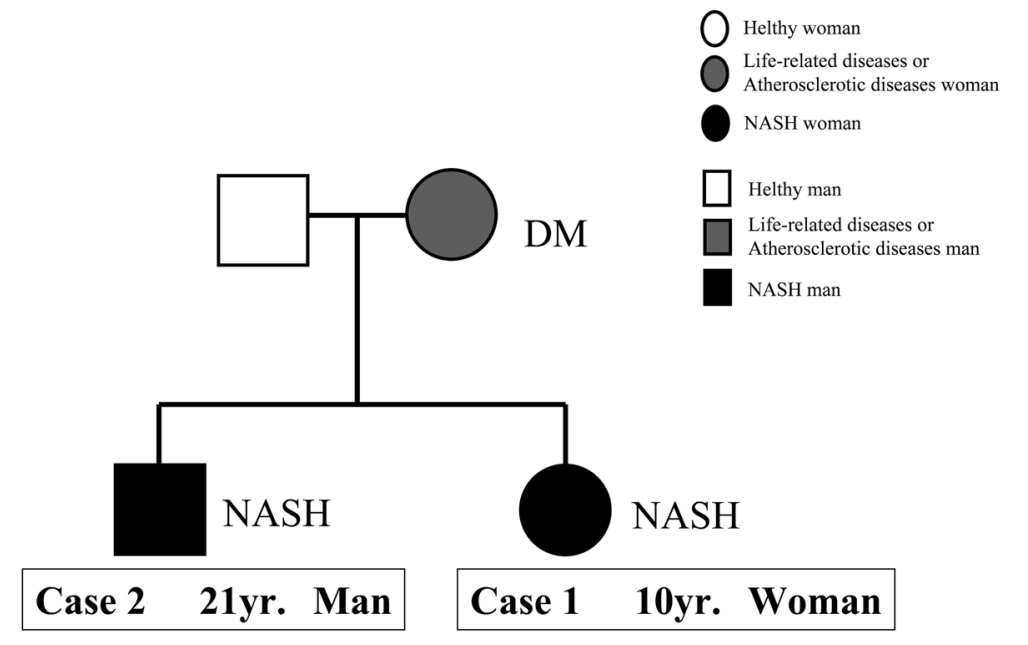

Figure 1. The family tree of family \#1. Cases 1 and 2 were diagnosed with NASH. Their mother had type 2 diabetes mellitus (DM).

Table 2. SNP Analysis

\begin{tabular}{|c|c|c|c|c|c|c|c|c|}
\hline $\mathrm{Tl}$ & $\begin{array}{c}\mathrm{F}-\alpha \mathrm{TNl} \\
-238 \\
\end{array}$ & $\begin{array}{l}F-\alpha \\
-308 \\
\end{array}$ & $\begin{array}{r}\text { TNF- } \alpha \\
-863 \\
\end{array}$ & $\begin{array}{r}\text { TNF- } \alpha \\
-1031 \\
\end{array}$ & $\begin{array}{l}\text { Adipo Adipo } \\
+45+276 \\
\end{array}$ & $\begin{array}{r}\text { IL-1 } \beta \\
+511 \\
\end{array}$ & Ad MTP & $\mathrm{MnS}$ \\
\hline Case 1 & $\mathrm{G} / \mathrm{G}$ & $\mathrm{G} / \mathrm{C}$ & & $/ \mathrm{C} \quad \mathrm{T} / \mathrm{T}$ & $\mathrm{G} / \mathrm{T} \quad \mathrm{G} / \mathrm{G}$ & $\mathrm{T} / \mathrm{T}$ & $\operatorname{Trp} / \operatorname{Arg} \mathrm{T} / \mathrm{G}$ & $\mathrm{T} / \mathrm{T}$ \\
\hline Case2 & $\mathrm{G} / \mathrm{G}$ & $\mathrm{G} / \mathrm{C}$ & & V/A $\quad \mathrm{C} / \mathrm{T}$ & $\mathrm{G} / \mathrm{T} \quad \mathrm{G} / \mathrm{G}$ & $\mathrm{C} / \mathrm{T}$ & $\operatorname{Trp} / \operatorname{Trp} \mathrm{G} / \mathrm{G}$ & $\mathrm{C} / \mathrm{T}$ \\
\hline Case3 & $\mathrm{G} / \mathrm{G}$ & $\mathrm{G} / \mathrm{C}$ & & $\mathrm{C} / \mathrm{A} \quad \mathrm{C} / \mathrm{T}$ & $\mathrm{T} / \mathrm{T} \quad \mathrm{G} / \mathrm{G}$ & $\mathrm{T} / \mathrm{T}$ & Trp/Arg G/G & $\mathrm{C} / \mathrm{T}$ \\
\hline Case4 & $\mathrm{G} / \mathrm{G}$ & $\mathrm{G} / \mathrm{C}$ & & VA $\quad \mathrm{C} / \mathrm{C}$ & $\mathrm{G} / \mathrm{T} \quad \mathrm{G} / \mathrm{G}$ & $\mathrm{C} / \mathrm{T}$ & $\operatorname{Arg} / \operatorname{Arg} G / G$ & $\mathrm{~T} / \mathrm{T}$ \\
\hline Case5 & $\mathrm{G} / \mathrm{G}$ & $\mathrm{G} / \mathrm{C}$ & & /C $\quad \mathrm{T} / \mathrm{T}$ & $\mathrm{G} / \mathrm{T}$ & $\mathrm{C} / \mathrm{T}$ & $\operatorname{Trg} / \operatorname{Trg} \mathrm{G} / \mathrm{G}$ & $\mathrm{T} / \mathrm{T}$ \\
\hline Case6 & $\mathrm{G} / \mathrm{G}$ & $\mathrm{G} / \mathrm{C}$ & & $/ \mathrm{C} \quad \mathrm{T} / \mathrm{T}$ & $\mathrm{T} / \mathrm{T}$ & $\mathrm{T} / \mathrm{T}$ & Trp/Arg G/G & $\mathrm{T} / \mathrm{T}$ \\
\hline
\end{tabular}

Shaded genotypes indicate those thought to contribute to the occurrence or progression of NASH or DM.

TNF, tumor necrosis factor

Adipo, adiponectin

IL-1, interleukin-1

$\beta 3$-Ad, $\beta 3$-adrenergic receptor

MTP, microsomal triglyceride transfer protein

and 4, there was no common tendency of lifestyle or food preference. Figure 3 shows the family tree of Cases 3 and 4. DM and hypertension were found in 3 other relatives. In the SNP analysis, both cases shared the SNPs of TNF- $\alpha$ promoter regions $-1,031$ and -863 , which have been suggested to be related to TNF- $\alpha$ production, and the SNPs of adiponectin gene, the $\beta 3$-adrenergic receptor and MTP genes, reportedly related to NASH (Table 2).

Family \#3 (Case 5, 34-year-old man; Case 6, 66-year-old woman)

Case 5 had been obese since primary school age. At age 24, his serum AST/ALT levels were slightly increased and his body weight had increased to $90 \mathrm{~kg}$ (BMI $28.7 \mathrm{~kg} / \mathrm{m}^{2}$ ). $\mathrm{He}$ was diagnosed with $\mathrm{DM}$ at age 29. As his control of DM was poor, medical treatment was started. In 2004, he was referred for hepatic dysfunction to our hospital. Laboratory and physical data showed BMI $33.5 \mathrm{~kg} / \mathrm{m}^{2}$, AST 66, ALT 69 (Table 1). Liver biopsy showed steatohepatitis
(Stage 3, Grade 3). We recommended diet and exercise therapy, after which his serum AST/ALT levels decreased. His mother (Case 6) had had hypertension from about age 50. At about age 60, hyperlipemia, hyperuricemia, and fatty liver were discovered. At age 63, therapy against DM was started. She was referred to our hospital for continuous hepatic dysfunction in 2005. Laboratory and physical data showed BMI $26.6 \mathrm{~kg} / \mathrm{m}^{2}$, AST 30, ALT 65 (Table 1). Liver biopsy showed steatohepatitis (Stage 3, Grade 3). In cases 5 and 6 , there was no common tendency of lifestyle or food preference. Figure 4 shows the family tree of Cases 5 and 6. DM and arteriosclerotic disease were found in 3 other relatives. In SNP analysis, both cases shared the SNPs of the MTP and MnSOD genes, which are reportedly related to NASH (Table 2). 


\section{Case 3 51yr. Woman}
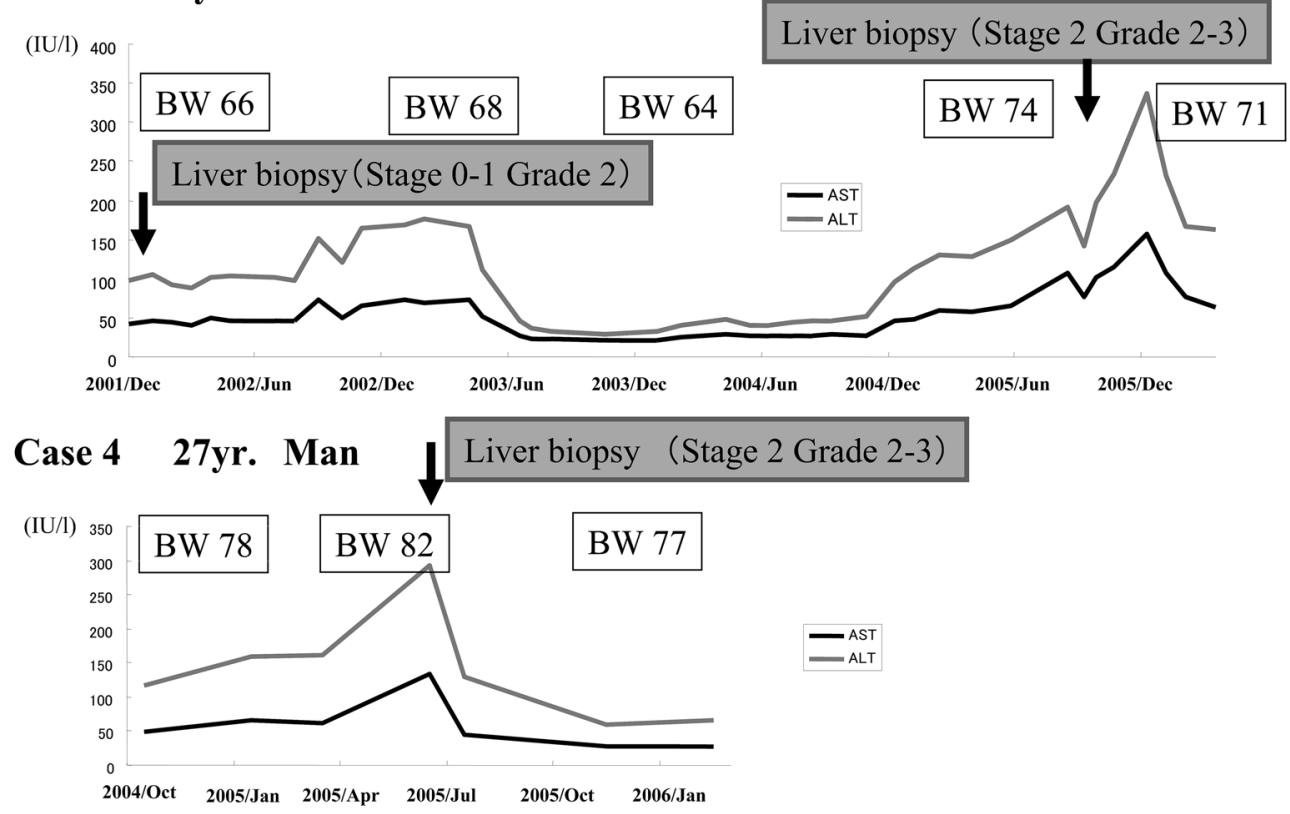

Figure 2. Clinical courses of cases 3 and 4 as well as the serum AST/ALT levels and body weight are shown. In case 3, the fibrosis stage progressed for 4 years. BW: body weight (kg).

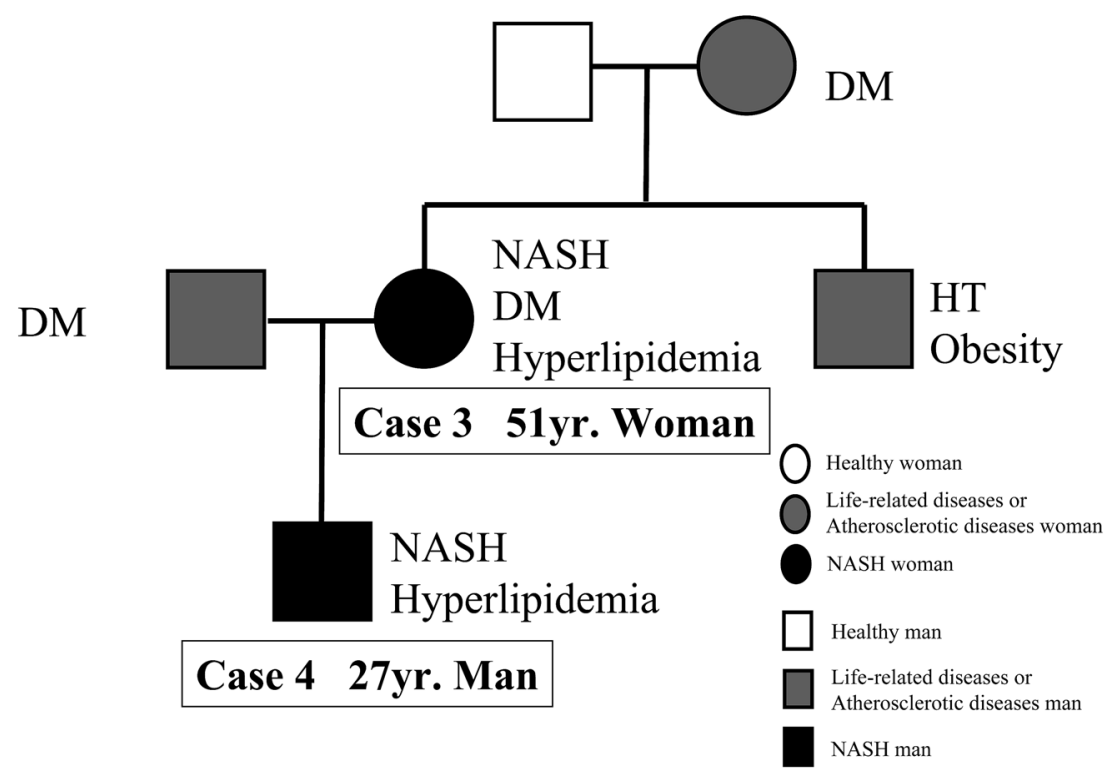

Figure 3. The family tree of family \#2. Cases 3 and 4 were diagnosed with NASH. The mother of case 3 and the father of case 4 had type 2 diabetes mellitus (DM).

\section{Discussion}

We encountered three families in which NASH occurred in two siblings, or in both parent and child, similar to other lifestyle-related diseases. In these families, DM and other lifestyle-related diseases were frequently observed. The NASH-associated SNP sites that were found in each family were different, but all patients had some SNPs that are reportedly related to NASH or DM. For example, in family \# 1, two SNP sites of adiponectin were shared between siblings, and each patient had other genetic SNPs. In family \#
2 , both patients shared an adiponectin gene SNP associated with $\mathrm{DM}$, an economizing genotype of the $\beta 3$-adrenergic receptor gene, a genotype of MTP that decreases the release capacity of very low-density lipoprotein (VLDL), and SNPs related to high TNF- $\alpha$ production. In family \#3, both patients shared SNPs of the MnSOD gene and MTP gene, which are associated with oxidative stress. It was not confirmed whether these SNPs actually contributed to the occurrence and progression of NASH in our patients. For example, case 2 did not show insulin resistance, raising suspicion as to whether the adiponectin gene contributed to the pathogenesis of NASH in this case. The biological function 


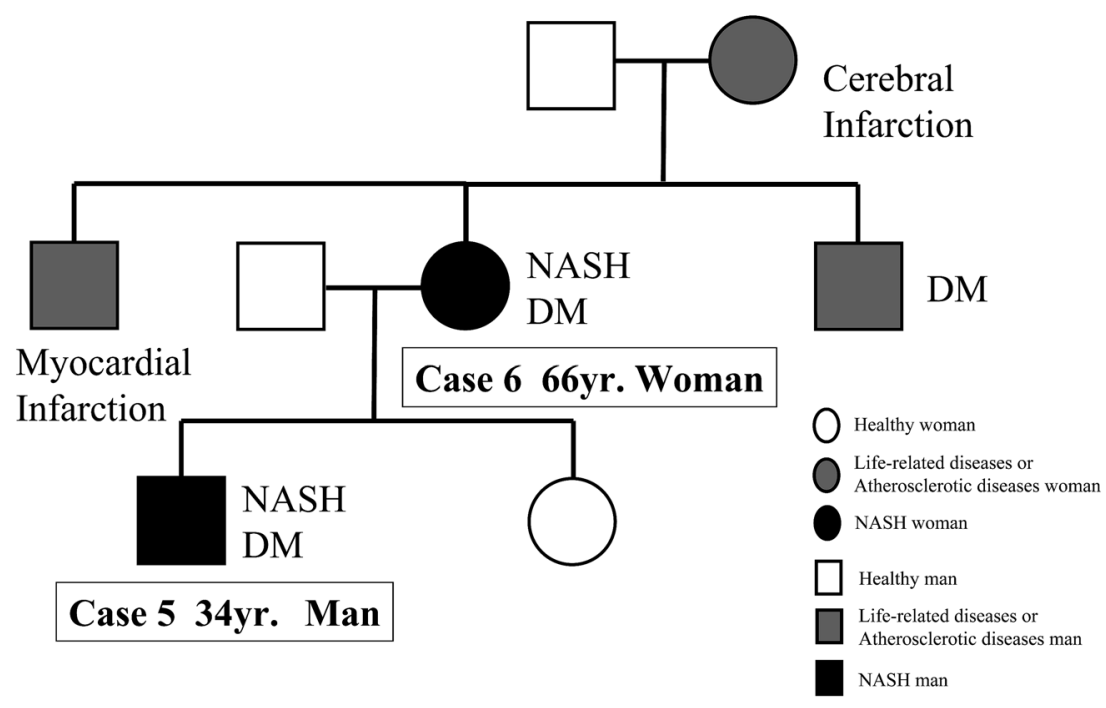

Figure 4. The family tree of family \#3. Cases 5 and 6 were diagnosed with NASH. The mother and brothers of case 6 had type 2 diabetes mellitus (DM) or atherosclerotic diseases.

of adiponectin has been associated with not only insulin resistance, but also anti-inflammatory and anti-liver fibrosis, and it has been demonstrated that adiponectin is associated with the occurrence and progression of NASH $(18,19)$. In addition, Hara et al reported that adiponectin SNP might influence the production of adiponectin (3). These data suggest that adiponectin and these SNPs are associated with NASH. Among the SNPs which are reported to be related to the pathogenesis and progression of NASH, only adiponectin SNPs were shared in Cases 1 and 2. Therefore, we suggest that adiponectin SNPs are associated with NASH. In the future, SNP analysis and investigation of lifestyles in other family members who have not developed NASH will clarify which factors are more important.

Abdelmalek et al reported that NAFLD patients were more likely to have DM and that insulin resistance and DM occurred frequently in their first-degree relatives. In addition, a trend toward insulin resistance was noted in the mothers, but not the fathers, of patients with NAFLD (11). In our three families, all mothers had DM and/or NASH. In addition, in families \#2 and \#3, the grandmothers had DM or atherosclerotic diseases. Yatsuji et al reported that DM was more prevalent in older female NASH patients and suggested the possibility that female NASH patients might have stronger genetic factors (20). At any rate, it is necessary to pay close attention to children of mothers with DM or NASH.

Familial aggregation has been reported for DM, insulin resistance, and arteriosclerotic diseases $(1,2,11)$. Here, in three family members, DM, HT, and arteriosclerotic diseases were frequently observed. These data support the hypothesis that NASH is associated with genetic background of these diseases and is part of the metabolic syndrome (12).

Case 5 was at stage 3 in young adulthood. In addition, the fibrosis of Case 3 progressed in the four years after diagnosis. Genetic background and similar eating habits or lifestyles might accelerate the progress of NASH. Considering the rapid progression of NASH in these patients, in addition to their family histories, amelioration of living habits and pharmacotherapy should be started from a young age.

Even when NASH patients had a genetic background for the disease, their liver function improved when body weight was controlled. These results suggested that adiposis based on living habits is the origin of NASH. We investigated the lifestyle and food preference by questionnaires. In cases 1 and 2 , both liked to eat snacks and ice cream. In cases 3 and 4, there was no common tendency of lifestyle or food preference. Cases 5 and 6 also showed no common tendency. More detailed investigations will be necessary, because the possibility could not be denied that a similar lifestyle might be the cause of NASH among members of the same family. As overeating is encouraged in contemporary society, it is believed that the incidence of NASH will increase in the future. It is also recommended for the entire family of a NASH patient to undergo medical examinations.

\section{References}

1. Altinli S, Elevli M, Ozkul AA, Kara PG, Karsidag K, Dogru M. Insulin resistance and metabolic syndrome in children of parents with diabetes mellitus. J Pediatr Endocrinol Metab 20: 431-436, 2007.

2. Bensen JT, Li R, Hutchinson RG, Province MA, Tyroler HA.
Family history of coronary heart disease and pre-clinical carotid artery atherosclerosis in African-Americans and whites: the ARIC Study: Atherosclerosis Risk in Communities. Genet Epidemiol 16: 165-178, 1999.

3. Hara K, Boutin P, Mori Y, Tobe K, et al. Genetic variation in the 
gene encoding adiponectin is associated with an increased risk of type 2 diabetes in the Japanese population. Diabetes 51: 536-540, 2002.

4. Turner MD, Cassell PG, Hitman GA. Calpain-10: from genome search to function. Diabetes Metab Res Rev 21: 505-514, 2005.

5. Zeggini E, Parkinson JR, Halford S, et al. Examining the relationships between the Pro 12 Ala variant in PPARG and type 2 diabetes-related traits in UK samples. Diabet Med 22: 1696-1700, 2005.

6. Kawamura T, Egusa G, Okubo M, Imazu M, Yamakido M. Association of beta3-adrenergic receptor gene polymorphism with insulin resistance in Japanese-American men. Metabolism 48: 13671370, 1999.

7. Kuriyama S, Tomonari H, Tokudome G, et al. Association of angiotensinogen gene polymorphism with erythropoietin-induced hypertension: a preliminary report. Hypertens Res 24: 501-505, 2001.

8. Prasad A, Narayanan S, Waclawiw MA, Epstein N, Quyyumi AA. The insertion/deletion polymorphism of the angiotensin-converting enzyme gene determines coronary vascular tone and nitric oxide activity. J Am Coll Cardiol 36: 1579-1586, 2000.

9. Teli MR, James OFW, Burt AD, Bennet MK, Day CP. The natural history of nonalcoholic fatty liver: follow-up study. Hepatology 22: 1714-1719, 1995.

10. Neuschwander-Tetri BA, Caldwell SH. Nonalcoholic steatohepatitis; summary of an AASLD single topic conference. Hepatology 37: 1202-1219, 2003.

11. Abdelmalek MF, Liu C, Shuster J, Nelson DR, Asal NR. Familial aggregation of insulin resistance in first-degree relatives of patients with nonalcoholic fatty liver disease. Clin Gastroenterol Hepatol 4: 1162-1169, 2006.
12. Willner IR, Waters B, Patil SR, Reuben A, Morelli J, Riely CA. Ninety patients with nonalcoholic steatohepatitis: insulin resistance, familial tendency, and severity of disease. Am J Gastroenterol 96: 2957-2961, 2001.

13. Struben VM, Hespenheide EE, Caldwell SH. Nonalcoholic steatohepatits and crptogenic cirrhosis within kindreds. Am J Med 108: 9-13, 2000.

14. Namikawa C, Shu-Ping Z, Vyselaar JR, et al. Polymorphisms of microsomal triglyceride transfer protein gene and manganese superoxide dismutase gene in non-alcoholic steatohepatitis. J Hepatology 40: 781-786, 2004.

15. Nozaki Y, Saibara T, Nemoto $Y$, et al. Polymorphisms of interleukin- $1 \beta$ and $\beta 3$-adrenergic receptor in Japanese patients with nonalcoholic steatohepatitis. Alcohol Clin Exp Res 28: 106S110S, 2004.

16. Tokushige K, Takakura M, Tsuchiya-Matsushita N, Taniai M, Hashimoto E, Shiratori K. Influence of TNF gene polymorphisms in Japanese patients with NASH and simple steatosis. J Hepatology 46: 1104-1110, 2007.

17. Brunt EM, Janney CG, Di Biscrglie AM, Neuschwander-Tetri BA, Bacon BR. Nonalcoholic steatohepatitis: a proposal for grading and staining the histological lesions. Am J Gastroenterol 94: 24672474, 1999.

18. Hui JM, Hodge A, Farrell GC, Kench JG, Kriketos A, George J. Beyond insulin resistance in NASH: TNF-alpha or adiponectin? Hepatology 40: 46-54, 2007.

19. Marra F, Aleffi S, Bertolani C, Petrai I, Vizzutti F. Adipokines and liver fibrosis. Eur Rev Med Pharmacol Sci 9: 279-284, 2005.

20. Yatsuji S, Hashimoto E, Tobari M, Tokushige K, Shiratori K. Influence of age and gender in Japanese patients with nonalcoholic steatohepatitis. Hepatol Res 37: 1034-1043, 2007.

(C) 2008 The Japanese Society of Internal Medicine http://www.naika.or.jp/imindex.html 